\title{
Bisulfite Sequencing
}

National Cancer Institute

\section{Source}

National Cancer Institute. Bisulfite Sequencing. NCI Thesaurus. Code C106054.

A DNA sequencing technique that can differentiate cytosine from 5-methylcytosine in a DNA sample. First, a denatured DNA sample is treated with bisulfite which converts nonmethylated cytosine to uracil. Next, the sample is amplified using a PCR method that does not discriminate between non-methylated and methylated sequences. The amplified DNA is subjected to nucleotide sequencing. The resulting sequence is compared to an identical control sample of DNA that was not treated with bisulfite. Unmethylated cytosines will be displayed as cytosines in the control sample and as thymines in the bisulfite-treated sample. 